\title{
DIÁLOGOS ENTRE GESTÃO EDUCACIONAL E PSICOLOGIA: REFLEXÕES PARA UMA PRÁXIS POSSÍVEL
}

\section{Alexandre Patricio de Almeida ${ }^{1}$ Luís Cláudio Figueiredo²}

RESUMO: Este artigo parte de um estudo de caso apresentado pelo autor, baseado em sua prática como gestor educacional, atrelada à sua formação como psicopedagogo e psicanalista. A partir de uma revisão bibliográfica específica, e com metodologia de abordagem qualitativa, ilustrada por meio de fragmentos do cotidiano escolar, objetiva-se demonstrar a importância do entendimento da gestão como uma tarefa coletiva e comprometida com uma educação integradora, que seja capaz de compreender a complexidade das relaçôes humanas, apresentada e desenvolvida pelos estudos da psicologia educacional. Propóe-se, por fim, uma reflexão direcionada para uma possível práxis interligada por via desse diálogo teórico.

Palavras-chave: Gestão educacional. Psicologia. Educação.

\begin{abstract}
This article is a case study presented by the author, based on his practice as educational manager, linked to their training as educational psychologist and psychoanalyst. From a specific literature review, and qualitative methodology, illustrated by daily school fragments, the objective is to demonstrate the importance of understanding management as a collective and committed task with an integrated education that is able to understand the complexity of human relations, presented and developed by studies of educational psychology. It is proposed finally a directed reflection for a possible praxis interconnected via this theoretical dialogue.
\end{abstract}

Keywords: Educational management. Psychology. Education.

1. Pedagogo, Psicopedagogo Clínico e Institucional, Psicanalista e mestrando em Psicologia Clínica no núcleo de Psicanálise da PUC-SP. Docente dos cursos de graduação em Psicologia e Pedagogia da Universidade Paulista - UNIP e Diretor Escolar da rede privada em São Paulo. E-mail: alexandrepatriciodealmeida@ yahoo.com.br

2. Mestre e Doutor em Psicologia Clínica. Professor do Programa de Psicologia Clínica da PUC-SP. 


\section{REFLEXÕES TEÓRICAS ENTRE GESTÃO EDUCACIONAL E PSICOLOGIA}

Não é de hoje que a gestão educacional vem ganhando um olhar mais democrático e flexível. Ao mesmo tempo, porém, que náo podemos deixar de citar a tradição que envolve a conceptualização desse cargo, e que ainda o faz ser considerado como o mais importante da carreira pedagógica. Em consequência dessa tradição e da posição de autoridade que envolve o diretor, muitas vezes o conceito de direção escolar é influenciado por diretrizes paradigmáticas que compóem a gestão empresarial. Dessa forma, muitos diretores assumem uma postura de centralização de decisóes e autoritarismo.

Uma direção que intimida, assim como um professor que repreende seus alunos com austeridade, acaba por gerar indivíduos inseguros. A insegurança por sua vez, produz uma redução das condições que envolvem a aprendizagem efetiva, pois, de fato, não há participação, muito menos interação entre os pares que se sentem, de certa forma, "amedrontados" por seus líderes. Libâneo (2004, p. 215) nos atenta para as funçóes que compete à direção pedagógica:

- Dirigir e coordenar o andamento e o clima dos trabalhos, assim como a eficácia na utilização dos recursos e meios, em função dos objetivos da escola;

- Assegurar o processo participativo de tomada de decisóes e cuidar para que essas decisóes se convertam em açóes concretas;

- Assegurar a execuçáo coordenada e integral das atividades da escola, com base nas decisóes tomadas coletivamente;

- Articular as relaçóes interpessoais na escola entre a escola e a comunidade (especialmente os pais).

O respectivo autor citado nos deixa evidente a importância de se pensar em uma prática coletiva, que além de envolver a todos da comunidade escolar, possa, ao mesmo tempo, considerar os diálogos existentes e possíveis que ocorrem no interior da escola.

Todavia, não podemos negar que principalmente em escolas particulares, exigem-se aspectos pertinentes à gestão empresarial para o diretor pedagógico, afinal uma instituição particular vive de lucros, e por consequência a administração financeira deve ocorrer de maneira efetiva, caso contrário, a falência poderá ser o resultado, ainda que inesperado e mais que isso, indesejado.

Entretanto, sabemos que a administração que ocorre em uma multinacional não é a mesma que deve se dar dentro do espaço escolar. Na escola lidamos com paradigmas educacionais; com 
indivíduos em crescimento (tanto físico, como social, cognitivo e pessoal); com valores que devem priorizar, sobretudo, a ética dos valores humanos, afinal o diretor é o maior exemplo a ser seguido.

Para repensarmos sobre essa modalidade de uma gestão mais democrática, mais humana, pode ser bastante produtivo pensarmos em uma direção pedagógica aliada aos conceitos da psicologia educacional. Neste caso, usaremos os conceitos desenvolvidos por Wallon que através de suas pesquisas nos incita a seguinte reflexão:

É responsabilidade do adulto, e principalmente do educador, adequar o meio escolar às possibilidades e necessidades infantis do momento. Assim, sua atuação torna-se psicológica, pois a orientação do ensino torna-se psicológica quando se pretende adaptarse ao espírito e à natureza da criança (WALLON, 1975, p.356).

Wallon nos mostra o quanto é necessário para o educador - e quando digo educador também incluo o diretor pedagógico - a capacidade de empatia, ou seja, de se colocar no lugar do outro, nessa instância apresentada por Wallon, especificamente, a capacidade de se por no lugar da criança. Vou mais além e me coloco a dizer que é primordial para uma gestão educacional participativa, a habilidade de se colocar no lugar de qualquer um dos integrantes que compóe o corpo intra e extraescolar: pais, professores, coordenadores, orientadores, auxiliares de limpeza e serviços gerais, etc. $\mathrm{O}$ diretor trabalha com toda equipe e saber adequar-se a cada demanda é fundamental.

A psicologia educacional nos remete também à ideia de que a ação da escola não deve se limitar à instrução, mas se dirigir à pessoa inteira e deve converter-se em um instrumento para seu desenvolvimento; esse desenvolvimento pressupóe a integração entre as dimensóes afetiva, cognitiva, emocional e motora. Assim, podemos pensar que uma criança, como também um professor, que se sente amparado, ouvido e compreendido por seu diretor se sentirá mais confiante em seu processo de aprender e ensinar, respectivamente. Wallon nos mostra que é através do meio físico e social que a atividade infantil encontra as alternativas de sua realização; o saber escolar não pode se isolar desse meio, mas sim, nutrir-se das possibilidades que ele oferece. Dessa forma, temos em mente, que um meio rígido, autoritário e individualista muito pouco terá a oferecer para a evoluçáo social das crianças e de toda equipe escolar.

Uma gestão democrática contribui para o equilíbrio emocional dos indivíduos que a integram. Uma pesquisa sobre exaustão emocional, realizada nos ambientes escolares, coordenada por Codo (2000), aponta para uma relação entre o estresse da equipe e o tipo de gestão realizado nas escolas:

[...] o tipo de gestão adotado pelas escolas é uma variável que 'intervém’ no cenário escolar, propiciando ou limitando o sofrimento psíquico dos trabalhadores. Mas, por quê? Quais os fatores derivados do tipo de gestão que fazem intermediação entre gestão e a exaustão emocional? [...] 
Nossa pesquisa mostrou haver a tendência de que [...] escolas de gestão tradicional mostram mais frequentemente diversos tipos de problemas [...]. Facilmente, pode se estabelecer um contraponto bastante claro entre este tipo de gestáo e a [...] democrática e participativa. De fato, todos os indicadores socioeducativos são mais problemáticos nas escolas que adotaram uma gestão do tipo tradicional, e vice-versa (CODO, 2000, p. 334, 335).

A pesquisa nos mostra o quanto "patológico" pode ser o ambiente predominante de autoridade e rispidez. Onde não há diálogo, não há o crescimento da criatividade e da liberdade de pensamento. Professores e diretores que não conversam entre si, acabam por prejudicar os principais atores do processo educativo: os alunos. É necessário que haja um espaço de escuta e interlocução, onde predomine a empatia e a capacidade de observar o outro como alguém que necessita de auxílio e compreensão.

No item a seguir, irei contar um caso que vivenciei em minha prática como diretor de escola, a fim de ilustrar o que apresentei até agora por meio da abordagem bibliográfica dos autores consultados. Trata-se de um caso que ocorreu, após a contratação de uma nova professora para compor o meu corpo docente.

\section{ESTUDO DE CASO: OS BENEFÍCIOS DE UMA GESTÃO PARTICIPATIVA}

Estávamos no período de janeiro, e consecutivamente, a fase de contratação de professores se iniciara. Precisava de uma professora de Ensino Fundamental para ser docente em uma nova turma que se formara, após a análise do currículo de algumas candidatas, optei por escolher uma que já tinha quatro anos de experiência em outra escola.

Ela começou o ano letivo e de início já apresentou um bom desempenho: era organizada, preocupada com seus alunos, cuidadosa com a integridade deles e bastante didática com o desenvolvimento dos conteúdos. Todavia, tinha algo nela que me preocupava: dificilmente ela vinha à minha sala me mostrar os seus trabalhos, ou tirar dúvidas sobre algo pertinente ao cotidiano escolar - apesar de sempre ser bastante educada e prestativa quando eu a abordava para fazer questionamentos sobre a turma.

Percebi certa timidez por parte dela: ela não se sentia confortável em vir falar comigo pessoalmente. Sempre recorria à coordenação da escola. Até que, em certo dia, não me contive e a chamei para conversarmos em minha sala. Perguntei a ela por qual motivo não tirava suas dúvidas comigo e que notava certa insegurança de sua parte em relação a mim. Ela me informou que na outra escola em que trabalhara a diretora náo permitia que os professores se dirigissem diretamente 
a ela, somente por intermédio da coordenaçáo, e que a diretora só tinha contato com a equipe em reunióes e eventos escolares. Fiquei ali naquele momento, pensando no que ela me havia dito, pois a minha concepção sobre direção escolar divergia demasiadamente da realidade que ela me contara. A meu ver, o diretor deve acompanhar o corpo discente e docente, se fazer presente entre toda equipe escolar, supervisionar a avaliação da produtividade da escola em seu conjunto e acima de tudo, gerir um ambiente saudável permeado pela escuta atenciosa e proporcionar um acolhimento emocional aos funcionários.

Disse à professora naquela ocasião, que ela não precisava ter essa concepção de direção escolar. Comentei que em nossa escola, as coisas funcionavam de outro jeito. Ela poderia contar com meu apoio, assim como dividir suas angústias perante as situaçóes cotidianas em relação à turma e a demanda de aprendizagem. Informei a ela, que a "sala da direção" era um espaço aberto, onde alunos e professores eram bem-vindos para conversar e se sentirem mais seguros. $\mathrm{O}$ trabalho em nossa instituição era coletivo, baseado na troca de ideias e tinha como objetivo o desenvolvimento pleno de nossos alunos.

A professora, naquele momento também ficou pensando em minhas palavras. Percebi que de certa forma, minha fala produzira uma reflexão em seus pensamentos. De fato, estava certo e pude notar isso no dia seguinte. A professora estava mais segura, veio em minha sala para mostrar a ideia de um projeto de leitura que pretendia desenvolver com a turma. Estava bastante empolgada. Ouvi e incentivei o trabalho, sugerindo também mais livros, além dos quais ela havia proposto para os alunos lerem em forma de "rodízio".

O tempo mostrou a ela que poderia confiar na direção da escola e contar conosco para compartilhar suas dúvidas, angústias e ansiedades, que são normais a qualquer ser humano. Wallon nos direciona a pensar que a escola não pode esquecer que toda prática verdadeiramente pedagógica tem por finalidade o desenvolvimento da pessoa e o fortalecimento do eu. Quando me disponho a ouvir meus professores e acompanhar o trabalho deles, me preocupo com esse conceito de fortalecimento da construção da personalidade. O diretor deve ter como objetivo de seu trabalho, levantar a autoestima de sua equipe, para que os integrantes tenham confiança em si e nos outros, estimulando uma ideia de respeito próprio e mútuo, enriquecido pela solidariedade.

\section{NOVAS REFLEXÕES PARA UMA POSSÍVEL PRÁXIS}

O diálogo entre teoria e prática deve se dar de maneira efetiva, sobretudo pela práxis de uma gestão participativa. A formação psicológica de nossos diretores não deve ficar limitada aos livros. "Deve ter uma referência perpétua nas experiências pedagógicas que eles próprios podem pessoalmente realizar”. (WALLON, 1975a: 366) Através dessa proposta Wallon estabelece sua posição de pensamento quanto às relaçôes entre Psicologia e Educação: são epistemologias que se diferem em paradigmas e estruturas, mas que se complementam para subsidiar a ação educativa. 
O diretor precisa lembrar que, acima de tudo, está lidando com seres-humanos e que por isso é essencial conhecer as teorias sobre o desenvolvimento, sobre a aprendizagem, sobre a construçấo da personalidade do indivíduo e o quanto as vivências escolares se tornam predominantes e influentes nesse processo. $\mathrm{O}$ diretor carece ter uma atitude permanente de investigador do ser em desenvolvimento e de sua própria ação pedagógica.

O profissional, à frente de uma escola, não pode ser um mero administrador. Precisa estar comprometido com uma ação transformadora, que movimente saberes capazes de desenvolver um processo de aprendizagem reflexivo, que consiga abranger a criatividade e o senso crítico. Só assim

podemos pensar em uma gestão aliada a psicologia escolar. Wallon (1975), sobretudo, ressalta que tornar o meio mais propício ao desenvolvimento de nossos alunos é nossa responsabilidade, essa ideia não é compatível com autoritarismo e rigidez, mas sim, com compreensão e sensibilidade. Por isso, é necessário que reflitamos sobre as nossas próprias atitudes, se quisermos propor uma transformação educacional, o primeiro passo deve partir de nós mesmos.

\section{REFERÊNCIAS}

CODO, W. (Coord.). Educação: carinho e trabalho. 2. Ed. Petrópolis: Vozes, 2000.

LIBÂNEO, J. C. Organizaçáo e gestáo da escola: teoria e prática. 5. Ed. Goiânia: Alternativa, 2004.

WALLON, H. A formação psicológica dos professores. Psicologia e educação da infância. Lisboa: Estampa (coletânea), 1973/1975.

L'evolution psychologique de l'enfant. Paris: Armand Colin, 1941/1968. 